\title{
Electrical Resistivity Studies on the Athabasca Glacier, Alberta, Canada
}

\author{
G. V. Keller and F. C. Frischknecht
}

(May 3, 1960)

\begin{abstract}
The use of electrical methods for measuring ice thickness and properties on the Athabasca Glacier, Alberta, Canada, has been studied by the U.S. Geological Survey. Two methods for measuring resistivity were tried: (1) a conventional resistivity method in which current was introduced galvanically into the glacier through electrodes, and (2) the other an electromagnetic method in which a wire loop laid on the ice was used to induce current flow. Results of the galvanic measurements showed large variations in the resistivity of the ice; in a surface layer several tens of feet thick the resistivity is between 0.3 and 1.0 megohm-meters, and under this layer, the resistivity of the ice is more than 10 megohm-meters. The resistivity of the surface ice is determined by its water content rather than by molecular resonance loss. The ice had no effect on the mutual coupling measurements in the frequency range from 100 to 10,000 cycles per second. As a consequence the electromagnetic data could be interpreted simply in terms of ice thickness and bedrock resistivity.
\end{abstract}

\section{Introduction}

Geological exploration in polar areas is often hampered by the presence of thick ice sheets covering rock outcrops. Geological studies in ice-covered areas are facilitated by the use of geophysical techniques to provide information about the rocks under the ice. Seismic, magnetic, and gravity methods are commonly used, but electrical methods have been used only rarely $[1,2]$, despite the fact that ice probably has more significantly different electrical properties than any rock with which it may be in contact.

An opportunity for studying the use of electrical methods over glacial ice came about during the summer of 1959, when the U.S. National Bureau of Standards planned a field study on Athabasca Glacier in Alberta Province, Canada, [3] and invited the U.S. Geological Survey to participate. The Athabasca Glacier was an attractive location for preliminary studies because of its accessibility and because an extensive program of glaciological work is being carried on there by the Universities of Alberta and British Columbia.

\section{Description of Athabasca Glacier}

The Columbia Ice Field, which is the source of the Athabasca Glacier, lies astride the British ColumbiaAlberta border, about $110 \mathrm{mi}$ north of the town of Banff, Alberta. Athabasca Glacier extends approximately $2 \frac{1}{2} \mathrm{mi}$ from the névé line at an elevation of $8,000 \mathrm{ft}$, to the toe at an elevation of $6,300 \mathrm{ft}$ (fig. 1). There are two ice falls in the first $3 / 4 \mathrm{mi}$ after the glacier leaves the ice field, each with a drop of several hundred feet. The lowermost step of the glacier is relatively flat and smooth for more than a mile before the ice surface drops off to the terminal lake.

${ }^{1}$ Contribution from U.S. Geological Survey, Denver 25, Colo.; paper presented at Conference on the Propagation of ELF Radio Waves, Boulder, Colo., January 25,1960 .

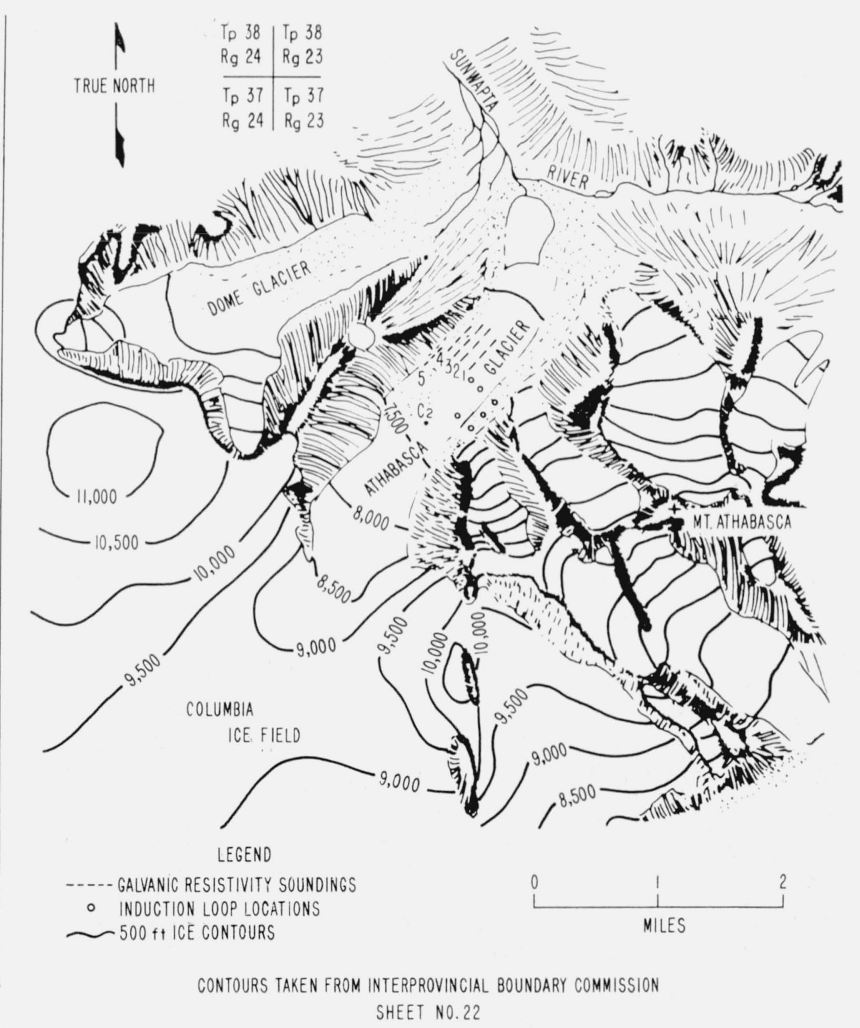

Figure 1. Sketch map showing the Athabasca Glacier.

The lower step is only slightly crevassed, though during the melt season parallel hummocks 3 to $5 \mathrm{ft}$ high, spaced at $10 \mathrm{ft}$ intervals, develop over most of the surface. Commonly, the valleys between these hummocks provide drainage for melt water. Drainage streams usually end in moulins, or melt holes, several hundred feet deep.

All of the electrical studies were carried out on the lower step, as indicated on figure 1 . 


\section{Field Work With Electrical Methods}

Two methods of measuring resistivity were used; one, a conventional method in which current was fed galvanically into the ice through electrodes, and the other, an electromagnetic method in which the mutual coupling between two wire loops laid on the ice was measured.

\subsection{Galvanic Method}

The galvanic measurements consisted of five depth soundings made at $300-\mathrm{ft}$ intervals across the glacier from the midpoint to the northwest margin, and a resistivity profile along this line (fig. 1). A fourterminal electrode system was used to make the depth soundings, with three of the four electrodes being fixed in position, and the fourth electrode $\left(P_{1}\right)$ being moved to increase the effective depth of the resistivity measurements (fig. 2 ). The electrodes $\left(C_{1}\right.$ and $\left.C_{2}\right)$ used to supply current to the ice were separated a distance of $2,500 \mathrm{ft}$, while the fixed voltage-measuring electrode $\left(P_{2}\right)$ was located 2,500 $\mathrm{ft}$ further down the glacier. The other voltagemeasuring electrode was placed at distances ranging from 5 to $1,600 \mathrm{ft}$ from the middle electrode.

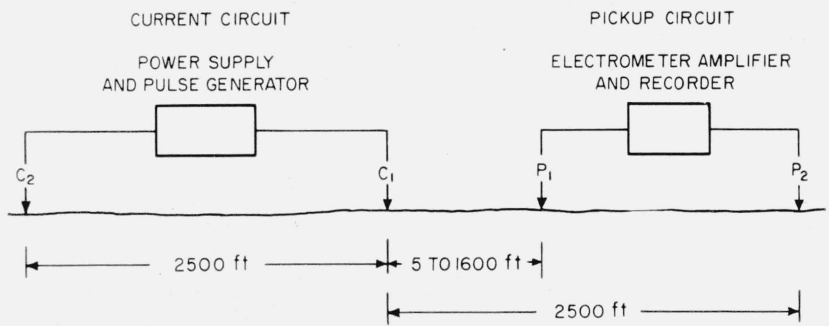

FIGURE 2. Block diagram of the single moving electrode array used in measuring ice resistivity.

Electrode $P_{1}$ is the only electrode moved in making a depth sounding.

The steel pins or lead rods used for electrode contacts in the ice, were usually placed in shallow melt ponds. Contact resistance which varied from location to location, was within the range 0.5 to 5 meg. Pulsed direct current, with a period of 0.1 to 3 sec, was used to energize the current spread, with the plateau current being approximately $1 / 2$ ma.

The voltage between the pickup electrodes was recorded on a hot-stylus oscillograph. Examples of some typical recordings are shown in figure 3 . Ideal voltage forms (fig. 3a) were recorded only at short spacings: the signal was large compared to background noise, and the transient rise and fall of the signal due to capacitance in the ice may be detected in spite of the switching transient. With large electrode separations the recorded signal was comparable in amplitude to the noise level (fig. 3b). Frequently, the recorded voltage form showed the effect of the capacitive surge of current from the wire connecting the current electrodes (fig. 3c). This surge became larger as the current cable melted into the ice, and the capacity between the cable and the ice increased.
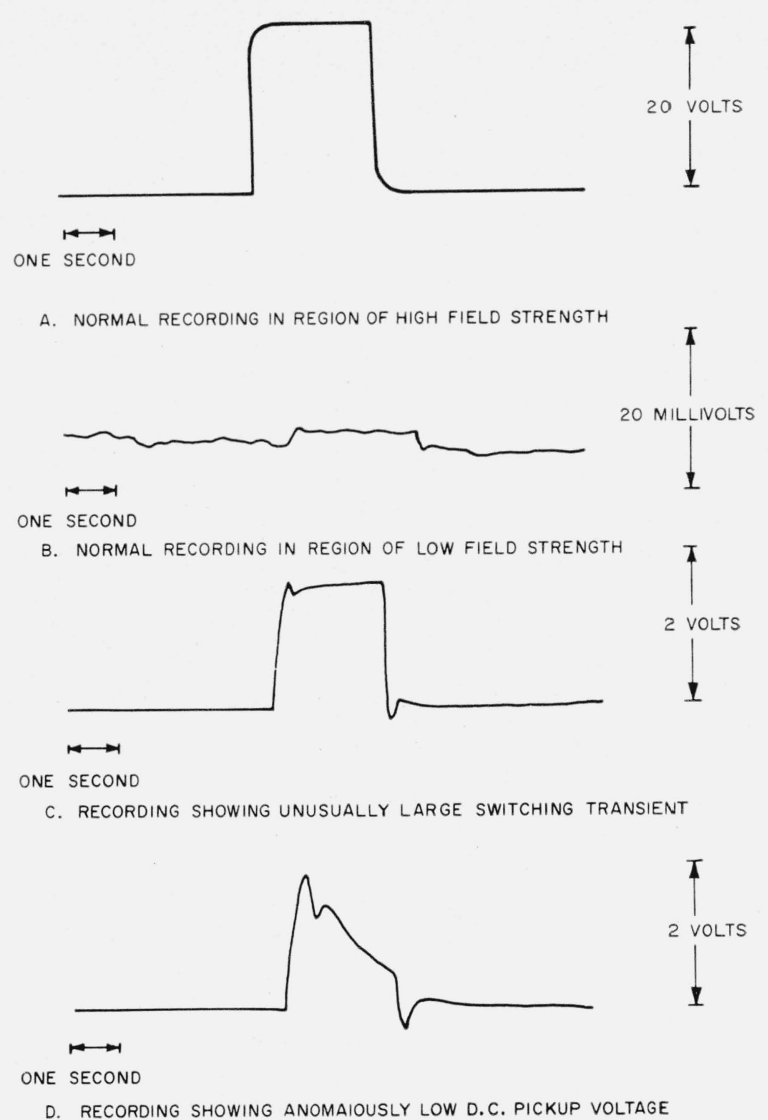

FiguRE 3. Examples of voltages recorded at the pickup electrodes during current pulses.

In a few cases, the recorded voltage form fell to a very low plateau value after the initial capacity surge (fig. $3 \mathrm{~d}$ ). It is possible that this type of voltage form occurred when the pickup electrode was located over a zone of highly resistant ice causing a very large source impedance to be in series with the recorder. Such high source impedances could not be detected by connecting an ohmmeter across the pickup terminals because the resistance measured in this way is that of a conducting surface film of water.

Both the apparent resistivity and the apparent dielectric constant of the ice can be calculated from the recorded voltages. Resistivity is calculated directly from the voltage, current and electrode geometry:

$$
\rho_{a}=2 \pi \frac{E}{I}\left(\frac{1}{\frac{1}{d_{1}}-\frac{1}{d_{2}}-\frac{1}{d_{3}}+\frac{1}{d_{4}}}\right)
$$

where

$\rho_{a}=$ the apparent resistivity for d-c current

$E=$ the plateau voltage

$I=$ the current

$d_{1}$ and $d_{2}=$ the distances between the moving electrode and the near and far current electrodes, respectively, 
$d_{3}$ and $d_{4}=$ the distances from the fixed pickup electrode to the near and far current electrodes, respectively.

The dielectric constant may be calculated from a Fourier analysis of the pickup-voltage form. The Fourier analysis gives the phase shift for the harmonics comprising the square wave pulse transmitted through the current electrodes. The apparent dielectric constant, is

$$
\epsilon=\frac{\tan \delta}{\rho_{a} \omega \epsilon_{0}}
$$

where

$\delta=$ the phase shift determined by Fourier analysis. $\rho_{a}=$ the apparent resistivity calculated from the same data.

$\epsilon_{0}=$ the dielectric constant for free space, $8.854 \times$ $10^{-12} \mathrm{f} / \mathrm{m}$.

$\omega=$ the angular frequency for which the phase shift is determined.

\subsection{Interpretation of Galvanic Resistivity Measurements}

The resistivities measured at one depth-sounding point near the northwest edge of the glacier are shown in figure 4 , plotted as a function of the current-

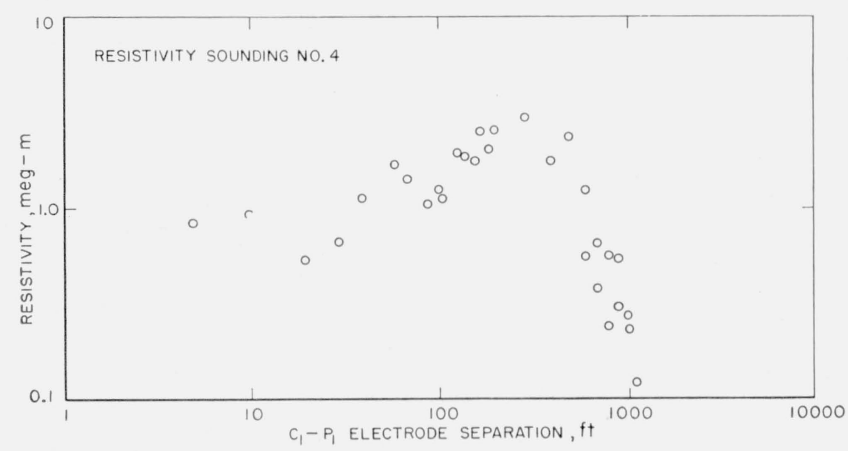

FIGURE 4. Example of resistivity depth sounding recorded on the Athabasca Glacier.

electrode pickup-electrode $\left(C_{1}-P_{1}\right)$ separation. The most striking feature of these data is the large amount of scatter, more than can be accepted if the data are to be used for quantitative interpretation. In spite of this scatter, the general form of the sounding is evident: it represents a surface layer with a resistivity of the order of $1 \mathrm{meg}-\mathrm{m}$, a second layer with a much higher resistivity, and a bottom layer of low resistivity.

Resistivity departure curves were prepared from tables given by Mooney and Wetzel [4] for this sequence of resistivities. An example of a family of such curves is shown in figure 5 for the case in which the resistivity of the second layer is 100 times that of the first layer and the resistivity of the third layer is 1/100 that of the first layer. Each curve represents a different thickness for the second layer. Such

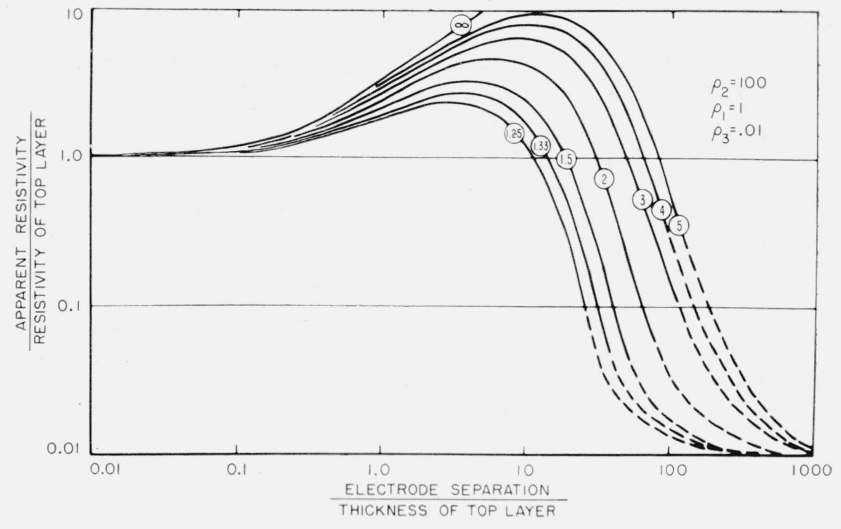

FIGURE 5. Theoretical curves of apparent resistivity as a function of electrode separation (computed from Wetzel [4]).

families of curves were prepared also for resistivity ratios between the three layers of $1: 10: 1 / 100$ and $1: 3: 1 / 100$.

It is difficult to compare the field measurements directly with these families of departure curves because of the large scatter in the data. The field data were smoothed by taking a running harmonic average of each consecutive set of six resistivity values. The five smoothed sounding curves are shown on figure 6 . Sounding 1, which was made

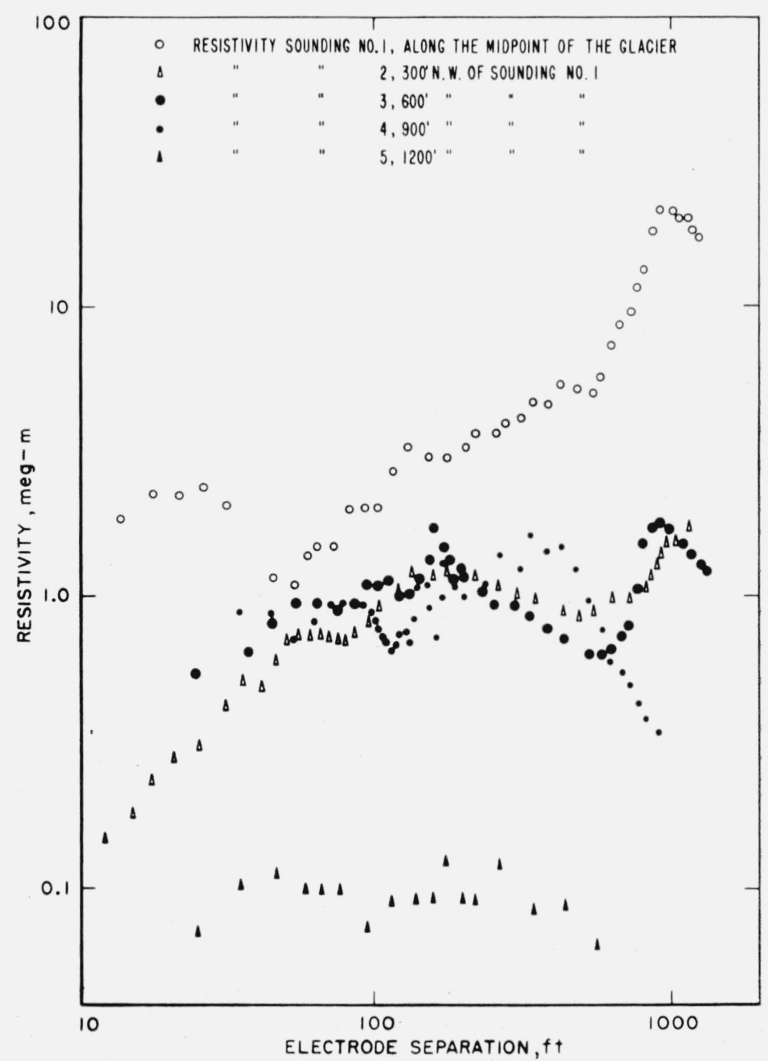

FIGURE 6. Resistivity sounding curves after forming a running average of each six consecutive resistivity values. 
along the center line of the glacier, showed much higher resistivities than any of the other soundings, with values ranging from $1.1 \mathrm{meg}-\mathrm{m}$ for relatively short spacings to $21 \mathrm{meg}-\mathrm{m}$ for relatively large spacings. Soundings 2,3 , and 4 show similar values of resistivity, one to another, though the resistivities recorded for sounding 4 (the closest of the three to the edge of the glacier), are significantly lower than for the other two soundings for the largest electrode separations. Sounding 5, which was recorded along the rubble-covered edge of the glacier, shows the lowest resistivities, approximately $0.1 \mathrm{meg}-\mathrm{m}$.

Field measurements which indicate a mediumhigh-low sequence of resistivities may be interpreted in the following manner. The initial portion of the sounding curve is matched with the initial portion of a family of three-layer curves, as shown in figure 5 . The shape of this initial portion of the curve is independent of the resistivity of the third layer, and if the thickness and resistivity of the second layer are greater than some threshold value, the initial shape is also independent of these parameters. By fitting only the first part of the field data, we may obtain values for the resistivity and thickness of the surface layer:

\begin{tabular}{c|c|c}
\hline \hline Sounding & $\begin{array}{c}\text { Resistivity of surface } \\
\text { layer }\end{array}$ & $\begin{array}{c}\text { Thickness of } \\
\text { surface layer }\end{array}$ \\
\cline { 1 - 2 } 1 & $\begin{array}{c}1.8 \times 10^{6} \text { ohm-m } \\
2\end{array}$ & $60 \mathrm{ft}$ \\
3 & 0.070 or $0.70 \times 10^{6}$ & 18 or 140 \\
4 & $.70 \times 10^{6}$ & 60 \\
5 & $.75 \times 10^{6}$ & 70 \\
$.070 \times 10^{6}$ & 50 \\
\hline
\end{tabular}

The form of sounding 2 indicates a very low resistivity in a thin surface layer which was not apparent in the other soundings. The other four soundings suggest the surficial layer of low resistivity is approximately $60 \mathrm{ft}$ thick and varies in resistivity from a high value of $1.8 \mathrm{meg}-\mathrm{m}$ at the center line of the glacier to a low value of $0.070 \mathrm{meg}-\mathrm{m}$ in the rubblestrewn margin of the glacier.

This variation in the resistivity of the surface ice in the glacier is further demonstrated by a resistivity profile which was measured along a line running from the midpoint of the glacier to the northwest edge (fig. 7). A constant electrode separation of $80 \mathrm{ft}$ was used, so the measured resistivity is controlled mainly by the thickness and resistivity of the surface layer. It is apparent that sounding 1 (fig. 6 ) was located in an area of high-surface resistivity, soundings 2,3 , and 4 in an area of low-surface resistivity, and sounding 5 in an area of very low surface resistivities.

The resistivity and thickness of the second layer indicated by the soundings were determined from the position and value of the maximum observed resistivity for each sounding. The spacing for which the maximum resistivity is observed is related to the thickness of the second layer (fig. 8). If the resis-
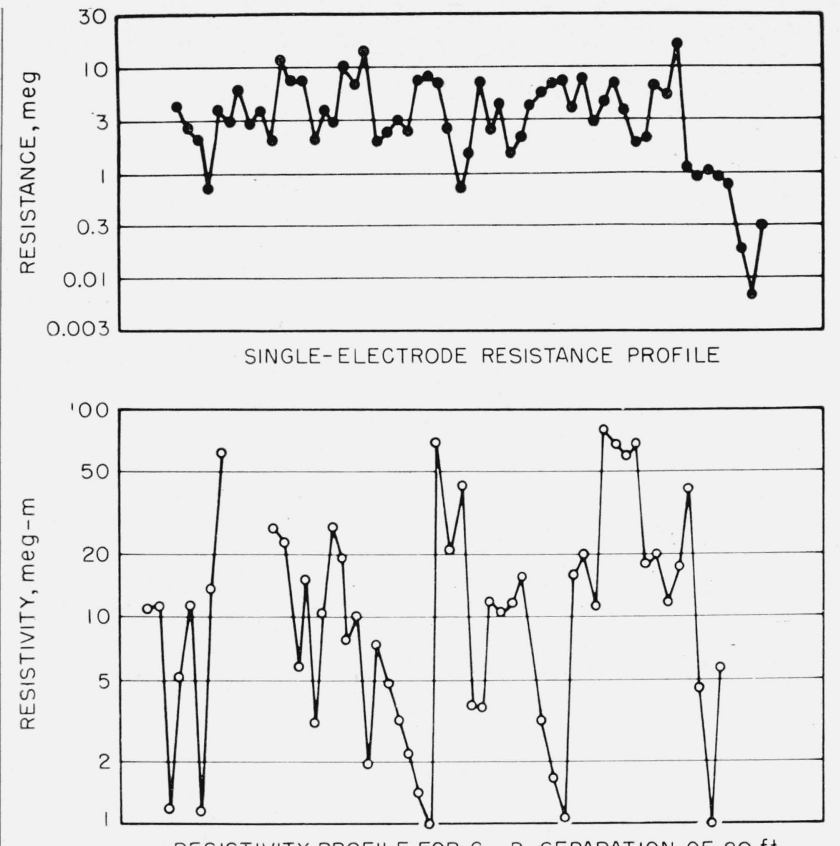

RESISTIVITY PROFILE FOR $C_{1}-P_{1}$ SEPARATION OF $80 \mathrm{f \dagger}$

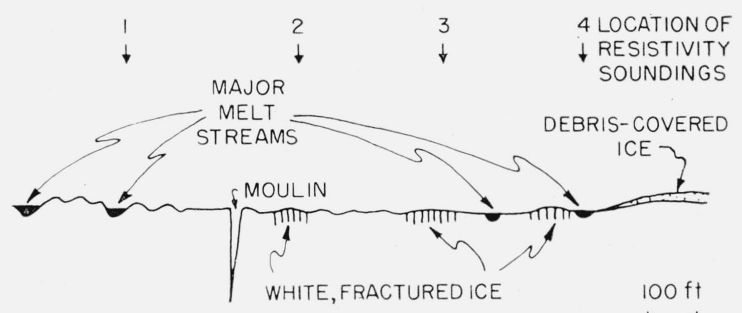

SURFACE FEATURES OF ICE ALONG RESISTIVITY PROFILE

FIGURE 7. Resistivity profile from the midpoint of Athabasca Glacier to the northwest edge, measured with a fixed electrode separation of $80 \mathrm{ft}$.

tivity of the second layer is very high, the maximum will be observed with electrode separations as much as three times greater than the combined thickness of the first and second layers. If the resistivity of the second layer is only 10 to 20 times greater than the resistivity of the first layer, then the maximum will be observed at an electrode separation about equal to the combined thicknesses of the first two layers.

The maximum observed resistivity will always be less than the true resistivity of the second layer for the sequence of resistivities observed on the Athabasca Glacier. Curves showing the relation between the maximum observed resistivity and the true resistivity of the second layer are presented in figure 9 .

The ragged shape of the observed sounding curves makes the selection of maximum values somewhat 
arbitrary. One set of reasonable values is:

\begin{tabular}{|c|c|c|}
\hline \multicolumn{3}{|c|}{ From field data } \\
\hline \multirow{2}{*}{ Sounding } & Maximum resistivity & \multirow{2}{*}{$\begin{array}{l}\text { Spacing at which maxi- } \\
\text { mum resistivity is } \\
\text { measured }\end{array}$} \\
\hline & Surface resistivity & \\
\hline $\begin{array}{l}1 \\
2 \\
3 \\
4 \\
5\end{array}$ & $\begin{array}{l}7.2 \\
2.9 \\
2.9 \\
2.1 \\
1.7\end{array}$ & $\begin{array}{c}1,000 \text { to } 1,500 \\
900 \text { to } 1,200 \\
800 \\
400 \\
250\end{array}$ \\
\hline \multicolumn{3}{|c|}{ Interpretation } \\
\hline Sounding & $\begin{array}{l}\text { Resistivity of } \\
\text { second layer }\end{array}$ & $\begin{array}{l}\text { Depth to bottom of } \\
\text { second layer }\end{array}$ \\
\hline $\begin{array}{l}1 \\
2 \\
3 \\
4 \\
5 \\
5\end{array}$ & $\begin{array}{l}22 \times 10^{6} \mathrm{ohm}-\mathrm{m} \\
11 \times 10^{6} \\
15 \times 10^{6} \\
21 \times 10^{6} \\
3.5 \times 10^{6}\end{array}$ & $\begin{array}{l}1,000 \mathrm{ft} \\
900 \\
800 \\
400 \\
250\end{array}$ \\
\hline
\end{tabular}

These measurements are in agreement with seismic determinations of the thickness of the glacier near the midpoint, where depths of approximately 1,000 $\mathrm{ft}$ were recorded (oral communication, P. J. Savage, Univ. of British Columbia). The bulk of the glacier appears to have a high resistivity, approximately 10 or 20 meg-m.

The electrode separations used were not large enough to determine the resistivity of the third, or

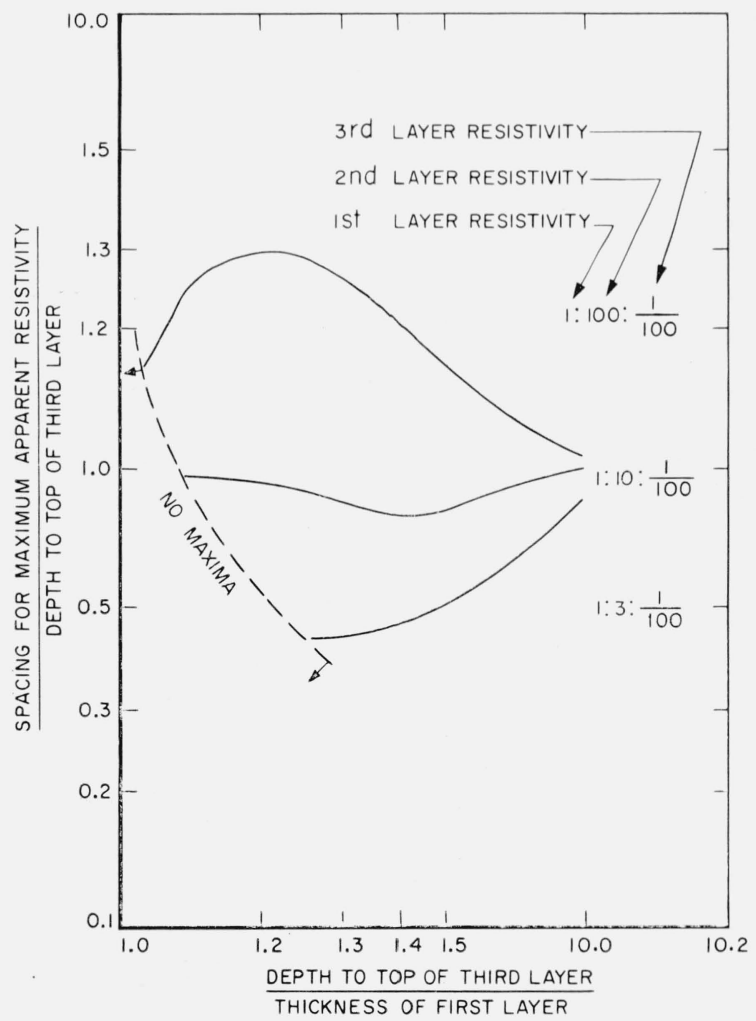

FIGURE 8. Relationship between the spacing for which maximum apparent resistivity is measured and the depth to the third layer for several ratios of resistivities.

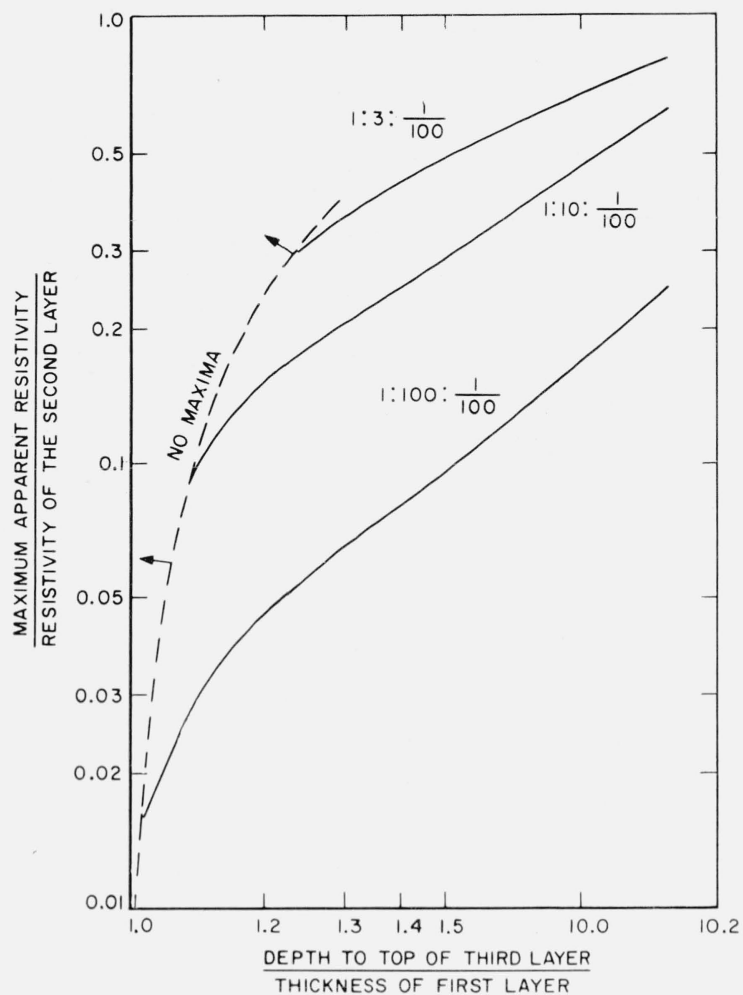

FIGURE 9. Maximum measured apparent resistivity as a function of the depth to the third layer for several sets of resistivity ratios.

bottom layer. However, the rate at which measured resistivity decreased at very large spacings indicates that the resistivity is $1 / 100$ (or less) than that of the surface layer. Resistivity of the bottom layer is, therefore, thought to be $7,000 \mathrm{ohm}-\mathrm{m}$ or less.

In summary, the data show that the glacier has a surface layer $60 \mathrm{ft}$ thick which is highly variable in resistivity, ranging from 0.07 to $80 \mathrm{meg}-\mathrm{m}$. Beneath this surface layer, the ice has a resistivity of 10 to $20 \mathrm{meg}-\mathrm{m}$. The lowermost layer has a resistivity of $7,000 \mathrm{ohm}-\mathrm{m}$ or less, and so, is probably bedrock.

The apparent dielectric constants for a depth sounding located at the middle of the glacier are shown in figure 10, plotted as a function of the $C_{1}-P_{1}$ separation. No theoretical curves are available for interpreting these data for an insulator over a conductor. However, data presented by Zablocki [5] suggest that if the surface layer in a section is much more resistant than the underlying medium, as electrode separations are increased, the apparent dielectric constant will first increase over the true value for the top layer and then decrease to the true value for the lower medium.

The lowest value of dielectric constant calculated from field data is approximately 140. The higher values indicated on figure 10 for $C_{1}-P_{1}$ separations of 100 to $1,000 \mathrm{ft}$ are probably caused by resistivity layering, which results in large interfacial polarization. 


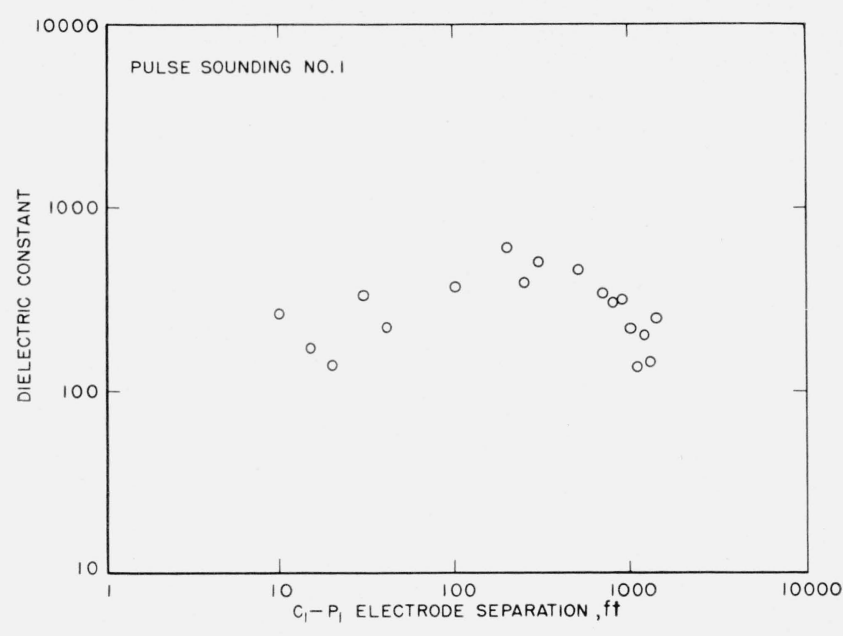

Figure 10. Apparent dielectric constant as a function of electrode separation.

\subsection{Electromagnetic Methods}

Electromagnetic soundings were made at five locations near the southeast edge of the glacier, as indicated by the pairs of small circles on the map in figure 1. The procedure consisted of measuring the mutual coupling between two loops of wire laid on the ice as a function of frequency in the range 100 to $10,000 \mathrm{c} / \mathrm{s}$ (fig. 11). An oscillator and a $70-\mathrm{w}$ audio

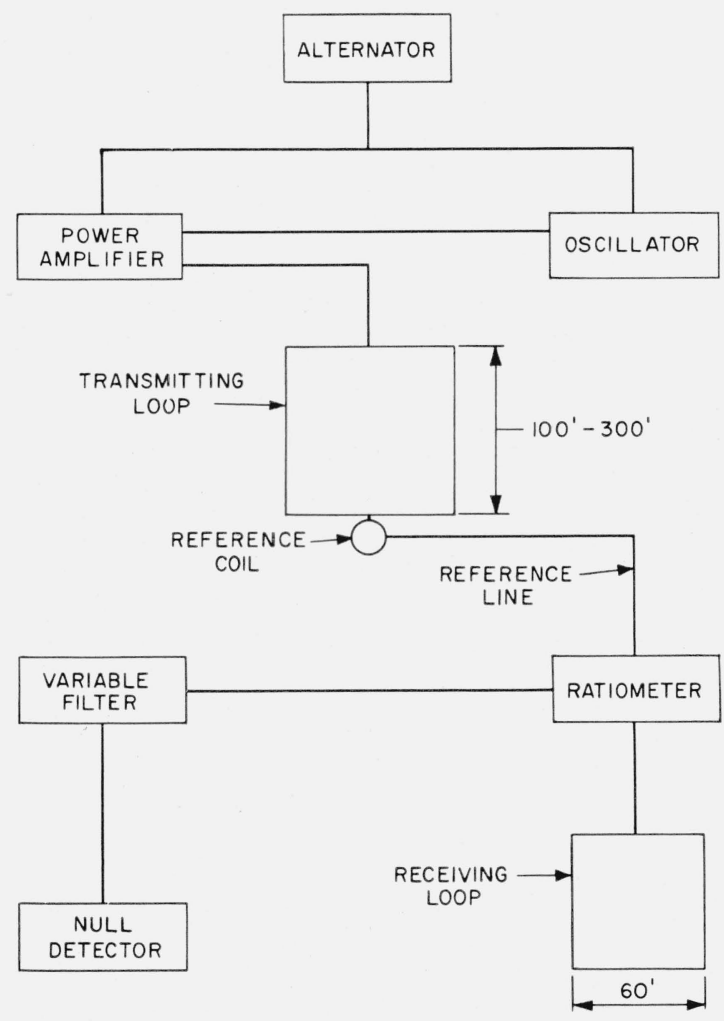

FIGURE 11. Block diagram of variable frequency electromagnetic apparatus. amplifier were used to supply several amperes of current to the transmitting loop, which consisted of 1 to 3 turns of wire, 100 to $300 \mathrm{ft}$ on a side. The receiving coil consisted of eight turns of wire with a braided shield and was $60 \mathrm{ft}$ on a side. The loops were separated by a fixed distance in the range from 500 to $1,820 \mathrm{ft}$ for each sounding. Neither loop was tuned.

A reference voltage, induced in a small coil placed at one side of the transmitting loop, was carried to the measuring apparatus over a two-conductor cable. The phase and amplitude of the received signal were compared with the reference voltage using a ratiometer and null detector. A variablefrequency bandpass filter was used to reduce interference from sferics and signals from a lowfrequency radio station at Jim Creek, Wash.

The amplitude ratios and phase differences observed at different frequencies are a function of the impedances of the receiving and reference coils and of the reference line. This dependence was determined by measuring the frequency response of the system with the coils very close together and with the reference line extended to its full length. All subsequent measurements were corrected for the frequency-dependence determined in this way.

Instrumentally, the only problem in making the field measurements was the difficulty in obtaining a sharp null at frequencies below about $300 \mathrm{c} / \mathrm{s}$ and above $3,000 \mathrm{c} / \mathrm{s}$. The difficulty at low frequencies was caused by low signal strength, and at high frequency by the high noise level from sferics and signals from the Jim Creek station. Amplitude ratios were measured with an accuracy of about \pm 2 percent at low frequencies. The phase angles and, above $3,000 \mathrm{c} / \mathrm{s}$, the amplitude ratios are of doubtful accuracy.

\subsection{Theoretical Curves for Electromagnetic Sounding}

Equations for the mutual coupling between horizontal loops lying on the surface of a homogeneous flat earth are given by Wait [6] for the case in which both the dielectric constant and the conductivity of the earth are important. The family of curves presented by Wait are plotted with the mutual impedance ratio, $Z / Z_{0}$ as a function of the parameter $B$, for various values of $b$, where

$$
B=\sqrt{\frac{\mu_{0} \omega r^{2}}{2 \rho}}
$$

$Z_{0}=$ mutual coupling between loops in free space

$b=\omega \rho \epsilon$

$Z /=Z / e^{i e}$ complex mutual coupling between these loops with the earth present

$|Z|=$ amplitude of the coupling with the earth present $\theta=$ phase angle of the coupling with the earth present

$\mu_{0}=$ magnetic permeability of free space $=4 \pi \times 10^{-7}$ $\mathrm{h} / \mathrm{m}$

$\omega=$ angular frequency 
$r=$ spacing between the loops

$\epsilon=$ dielectric constant of the earth

$\rho=$ the resistivity of the earth=reciprocal of conductivity.

These theoretical curves may be compared with field curves of mutual coupling measured as a function of loop separation, but with the frequency held constant. In the present work, mutual coupling was measured as a function of frequency with the loop spacing held constant. In order to plot coupling curves, which vary with frequency rather than spacing, we permit $b$ to vary proportionally with $B^{2}$ :

$$
b=A B^{2}
$$

where $A$ is an arbitrarily selected constant, instead of holding $b$ constant. Referring to the definitions of $b$ and $B$, we see that this is equivalent to:

$$
\frac{2 \rho^{2} \epsilon}{\mu_{0}}=A r^{2}
$$

and since $\rho, \epsilon, \mu_{0}$, and $A$ are constants, this means $r$ must be constant for this particular curve relating coupling to the ratio $B$. Figure 12 shows two families of coupling curves, one calculated for constant values of the ratio $b$, and the other calculated for sets of values of $b$ proportional to $B^{2}$. These sets of curves are valid only if the coil spacing, $r$, is larger than the height of the loops above bedrock.

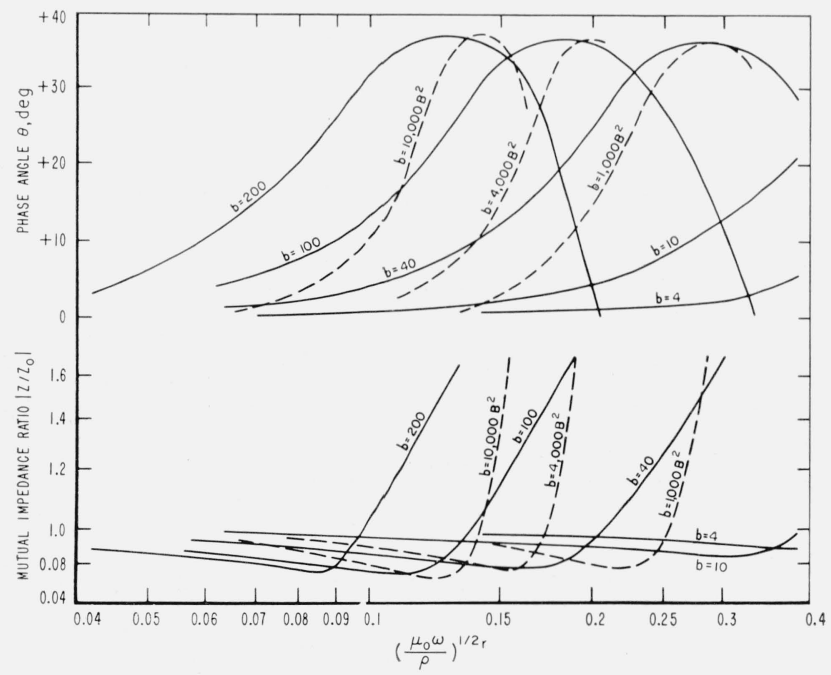

Figure 12. Mutual impedance plotted as a function of the conductivity parameter for two horizontal loops on a lossy dielectric earth (calculated from Wait [7]).

In reference 17] Wait gives equations and some computations and curves for the case in which the loops are raised above a conducting homogeneous earth, but with the effect of dielectric constant neglected. Slichter and Knopoff [8] have presented equations and computations for the case in which loops are placed on the surface of a conducting two layer earth. This case degenerates into the preceding case, considered by Wait, if the conductivity of the upper layer is zero. In both cases, the mutual coupling is presented as a function of loop separation rather than of frequency. They may be replotted as a function of frequency, but they do not cover adequately the range of interest.

Wait [9] has derived equations for the coupling of loops raised above a two-layer earth. This equation has been evaluated for a large number of cases by the Computations Branch, U.S. Geological Survey. The results are plotted as families of curves with mutual impedance $Z / Z_{0}$ plotted as a function of $B$, for various parametric values of the ratios $h / r, d / r$, and $K=\rho_{1} / \rho_{2}$ where

\section{$h=$ height of the loops above the earth \\ $d=$ thickness of the upper layer}

$\rho_{1}$ and $\rho_{2}=$ resistivities of the upper and lower layers, respectively.

A family of curves for horizontal loops raised above homogeneous earth $(K=1)$ is shown in figure 13 .

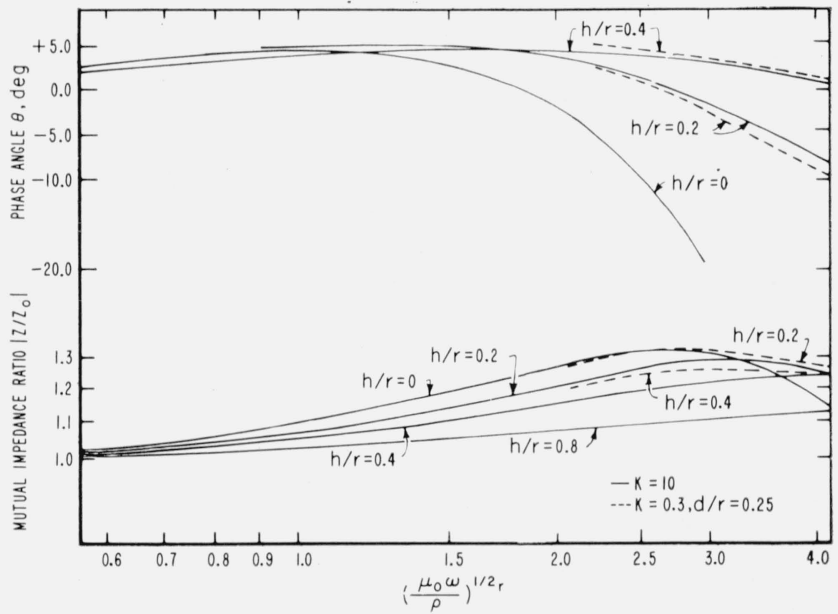

Figure 13. Mutual impedance plotted as a function of the conductivity parameter for two horizontal loops raised above a two-layer conducting earth (calculated from Wait [9]).

Portions of curves for loops raised above a twolayered earth with $K=0.3$ and $d / r=0.25$ are also shown in figure 13 as dashed lines. If it can be assumed that the ice is an insulator, then the measurements made on Athabasca Glacier can be treated as a case in which the loops are raised over a conducting earth by a distance equal to the thickness of the ice. The field data then could be compared with the families of curves shown in figure 13 . Neither the curves in figure 12 or figure 13 apply to the case of a lossy dielectric over a conducting earth, but each set is an approximation to the two limiting cases, one where the ice is very thick, and the other where the loss in the ice is very small.

Relative to the theoretical curves, both the abscissa and the ordinate of the measured curves contain undetermined constant multipliers. In normalizing the field curves by making measurements with the loops close together, the free-space mutual coupling, $Z_{0}$, is determined. However, since $Z_{0}$ 
varies as the cube of the separation between the loops, it is not possible to calculate an accurate value of $Z_{0}$ for a large spacing from the value determined at a small spacing. Therefore, the ordinate of the field curve is $\psi_{1} Z / Z_{0}$, where $\psi_{1}$ is undetermined. Similarly, the abscissa of the field curves is $f$ rather than $B$, so $B=\psi_{2} \sqrt{f}$, where $\psi_{2}$ is not known.

In interpretation, the field curves and the theoretical curves are plotted on separate sheets of log-log graph paper. The field curve is laid over a family of theoretical curves until a good match is found with one of the theoretical curves. If a valid fit between curves is found, $\psi_{1}, \psi_{2}$ and the other parameters are readily determined. The position of the ordinate of the field curve relative to the theoretical curve determines $\psi_{1}$; the position of the abscissa determines $\psi_{2}$, from which $\rho$ may be calculated. The particular theoretical curve which is matched specifies $\omega \rho \delta$ or $h / r$, depending on which type of curve is used. If the field curve can be extrapolated to zero frequency, $\psi_{1}$ may be determined from the relationship $\psi_{1}\left(Z / Z_{0}\right)=1$. If $\rho$ is known by some independent measurement, $\psi_{2}$ and $B$ can be determined without curve matching.

\subsection{Results of Electromagnetic Soundings}

The first two soundings were made with a $500-\mathrm{ft}$ coil separation over a section of the glacier where the ice is known to be at least $800 \mathrm{ft}$ thick. The data from one of these soundings is shown as curve $a$, in figure 14 . The maximum change in coupling with

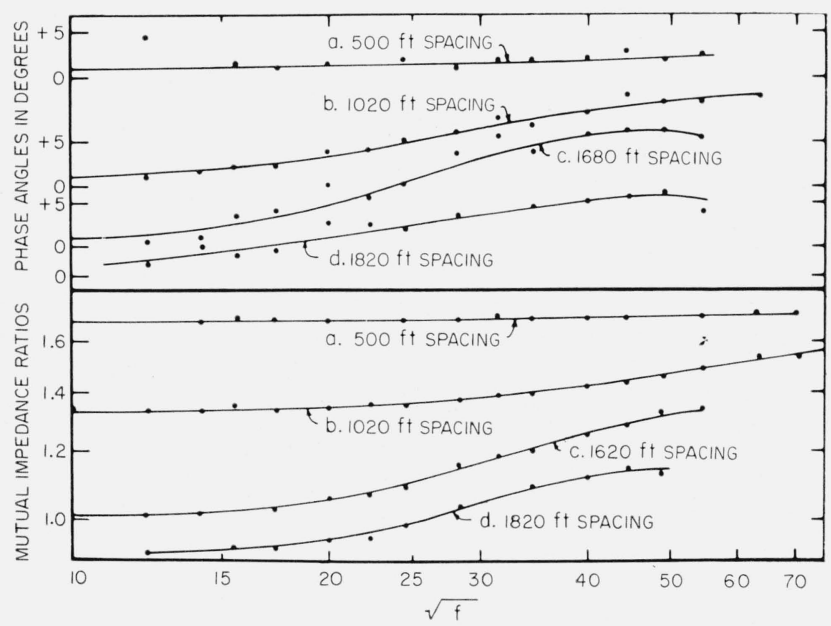

Figure 14. Changes in mutual impedance (as a function of the square root of frequencies) measured on the Athabasca Glacier.

change in frequency is about one-half percent, which is the approximate range of scatter of the data. The soundings with relatively close spaced loops showed that the ice had a negligible effect on coupling, so that it would be impossible to use the curves in figure 13 for interpretation.

The rest of the measurements were made with larger loop separations with the loops alined along the length of the glacier near the southeast edge (fig. 1). The data are shown as curves $b, c$, and $d$, in figure 14. Soundings $b$ and $c$ were made at the same distance from the edge of the glacier.

The data for soundings $b$ and $c$ are superimposed on theoretical curves for horizontal loops raised above a conducting earth in figure 15. Only the amplitude

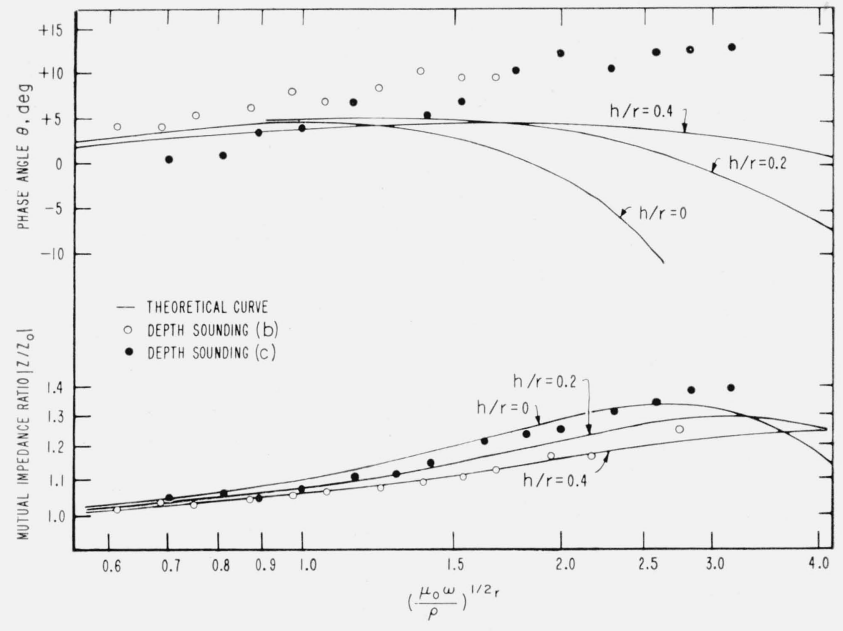

Frgure 15. Comparison of data from Athabasca Glacier with theoretical curves (calculated from Wait [9]) for horizontal loops raised above a two-layer conducting earth.

curve for sounding $b$ matches the theoretical curves well; the amplitude curve for sounding $c$ and the phase curves for both soundings do not fit the theoretical curves.

Three possible explanations for the departure of these sounding curves from the theoretical curves have been considered: (1) layering within the bedrock, (2) a dipping surface at the bottom of the glacier, and (3) response from the ice. It is likely that the dipping contact at the base of the glacier is the most important of the three factors. This dip may be as much as 30 or $40 \mathrm{deg}$, so the approximation of horizontal loops raised over the horizontal surface of a conducting earth is in error. A better approximation may be obtained by replacing the horizontal loops with two sets of component loops, one set with their axes parallel to the bedrock surface and the other set with their axes perpendicular to the bedrock surface. Figure 16 shows the soundings $b$ and $c$ superimposed on theoretical curves for loops inclined at $45 \mathrm{deg}$ to the surface of the earth. The measured and theoretical amplitude curves match well, and while the match with the phase curves is not perfect, it is better than that shown in figure 14 .

The amplitude curves may be interpreted as follows: for sounding $b$, we find that $h / r \cong 0.50$, and since $r=1,020 \mathrm{ft}, h \cong 510 \mathrm{ft}$. The abscissa position gives a value for the resistivity of the bedrock as $670 \mathrm{ohm}-\mathrm{m}$. For sounding $c$, we find that $h / r \cong 27$, and since $r=1,680 \mathrm{ft}, h \cong 454 \mathrm{ft}$ and $\rho=530 \mathrm{ohm}-\mathrm{m}$. These values for soundings $b$ and $c$ compare reasonably well, particularly, since observation of the edge of the glacier indicates that the bottom surface is irregular. 


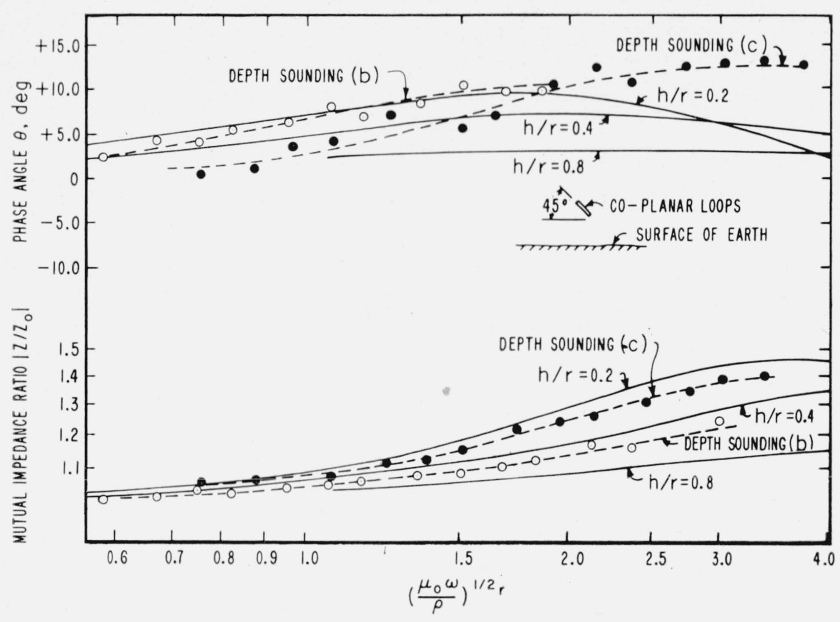

Figure 16. Comparison of data from Athebasca Glacier with theorectical curves (calculated from Wait [9]) for coplanar inclined loops raised above a homogeneous conducting earth.

\section{Summary of Electrical Properties of Athabasca Glacier}

Extensive laboratory studies of the electrical properties of ice have been reported in the literature (see, for example, Smythe and Hitchcock [10]). The ice molecule is polar, and exhibits molecular resonance at audio and lower frequencies at subzero centigrade temperatures. The relationships between dielectric constant and frequency and between resistivity and frequency as found by Smythe and Hitchcock for ice near the melting point are shown by the two solid curves in figure 17. At low fre-

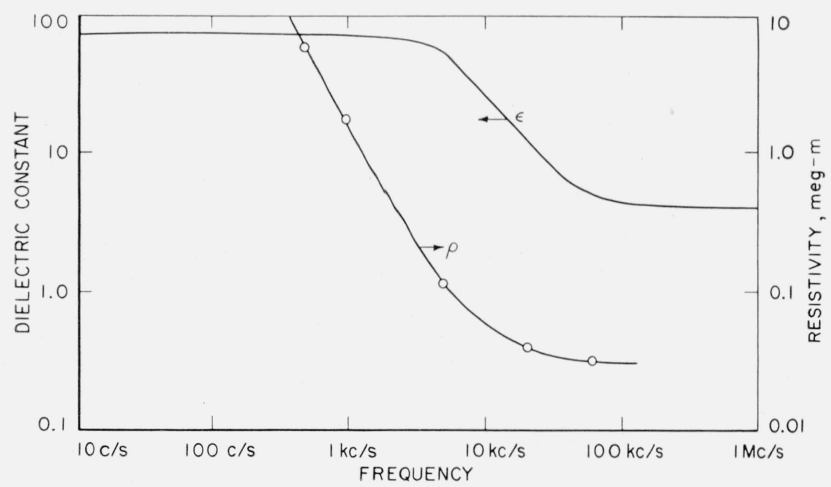

FIGURE 17. Summary of the electrical properties of ice slightln below the freezing point (data from Smythe and Hitchcock, 1932).

quencies, the dielectric constant is 73.7 , while at high frequencies, it is 4.0 . The relaxation frequency of the dispersion is $15.5 \mathrm{kc} / \mathrm{s}$.

As in any case of molecular resonance, the relaxation frequency is also the frequency at which the highest loss is observed. At high frequencies, the resistivity of the ice approaches a constant value, 0.0335 meg-m. At frequencies below the relaxation frequency, the resistivity increases as the inverse square of the frequency. At zero frequency, the resistivity is infinitely large.

In the measurements on Athabasca Glacier, it was found that the resistivity of the ice at low temperatures is finite and for the surface layer ranges from 0.3 to $1.0 \mathrm{meg}-\mathrm{m}$. This can be attributed to the fact that glacial ice has a different genesis than the ice usually studied in the laboratory. For the most part, glacial ice is compacted snow rather than frozen water. In this respect, glacial ice resembles any other detrital rock. In general, glacial ice will have considerably more pore space than crystalline ice, and during the melt season, these pores may contain water.

There are three types of porosity apparent in glacial ice: (1) crevasse porosity, (2) vugular or melt cavity porosity, and (3) microporosity. An open crevasse might be expected to increase the resistivity of the ice greatly. On the lower part of the Athabasca Glacier, most of the fractures are not open, and are probably filled with a thin film of water, affording a path for conduction. Even if the glacier is slightly below the melting point, these fractures may contain water. Since the fractures absorb the downward motion of the glacier, there may be pressure melting of ice where irregularities on either side of a fracture bear the brunt of the down-glacier pressure.

In many respects, the porosity of glacial ice resembles the porosity in limestones, which also have three types: (1) intercrystalline microporosity, (2) vugs or solution cavities, and (3) joints. It seems reasonable that the equation relating water content and resistivity in limestones might be applied to ice:

$$
\rho=1.4 \rho_{w} S^{-1: 8}
$$

where $\rho_{w}$ is the resistivity of the water contained in the rock and $S$ is the volume fraction of water in the rock.

Samples of water taken from the runoff streams on the glacier were found to have a resistivity of 650 ohm-m at $0^{\circ} \mathrm{C}$. Assuming eq (3) applies to glacial ice, we may calculate that ice with a resistivity of 0.3 meg-m has a water content of 4.0 percent by volume.

Fine-grained detrital rock material in ice can lower the resistivity considerably, because such impurities can retain water in a liquid state even well below freezing. Parts of the Athabasca Glacier appear to include high concentrations of rock, particularly along the lateral moraines where landslides have covered the margins of the glacier with rock. These zones were found to be 10 to 100 times more conductive than the clean ice, but this conductivity extended only a few inches or few feet into the ice.

At low frequencies, it is apparent that the resistivity of the ice is determined by the moisture content rather than by molecular resonance. At some frequency, the molecular loss must become more important than conduction through the water, since at high frequencies, the conduction caused by molecular losses is ten times greater than the conduction through the water. 


\section{Conclusions}

Resistivity studies on Athabasca Glacier indicate that electrical methods may be useful in studying the thickness and texture of temperate-glacial ice. Electromagnetic methods are probably preferable to galvanic methods if the primary interest is in the thickness of the ice and the nature of the underlying material.

The electromagnetic method described here can probably be used over thicker glaciers or ice caps with equal success. The limiting factor in using the method over very thick ice will be the response from the ice itself. It would be possible to calculate coupling curves taking into account the loss in the ice, but probably the effect of the loss in the ice would mask the small response from the conductive earth under the ice for those ice thicknesses where loss in the ice becomes important.

In order to use this electromagnetic method on an ice cap four times as thick as the Athabasca Glacier, the coil separation would have to be increased by a factor of 4 to maintain a favorable ratio, $h / r$. The frequency range would have to be lowered by a factor of 16 to stay in the same range of values for the parameter $B$. Therefore, the product $\rho \omega \epsilon$ for the ice could be 16 times larger than on the Athabasca Glacier and yet cause no more distortion of the observed data.

In many areas, bedrock resistivities may be larger than $600 \mathrm{ohm}-\mathrm{m}$. The frequencies used in sounding must be increased in a direct ratio to the bedrock resistivity in order to stay in the same range of values of $B$. If the bedrock resistivity were too large, such high frequencies might be required that some response would be obtained from the ice itself.

If primary interest is in the properties of the glacial ice rather than bedrock, galvanic resistivity measurements are preferable. In this study, it was found that resistivity measurements could distinguish between zones of massive ice and zones of compacted névé, and so, may be helpful in tracing structure in a glacier. Resistivity measurements may be used to detect the depth to which a glacier contains liquid water. As corollary, it may be possible to measure thermal layering in a glacier by measuring the resistivity layering.

The authors are indebted to James Wait and Donald Watt, of the National Bureau of Standards, for suggesting the work on Athabasca Glacier; to George Garland of the University of Alberta, for his invitation and offer of assistance; and to the Department of Northern Affairs and National Parks of the Commonwealth of Canada for permission to work in Jasper National Park. We especially appreciate the assistance given by W. R. Ruddy of Snowmobile Tours, Ltd., in providing transportation on the glacier.

\section{References}

[1] C. Lefevre, P. Albertinoli, A. Bauer, A. Blum, L. Cagnaird, and H. Fournier. Measures electriques et telluriques sur le grand Glacier D'aletsch, Ann. de geophys., 13, 54 (1957).

[2] C. Queille-LeFevre, A. Bauer, Girard, Premier essai de mesure electrique d'epaisseur d'un glacier, Ann. de geophys, 15, 564 (1959).

[3] A. D. Watt, and E. L. Maxwell. Measured electrical properties of snow and glacial ice, J. Research NBS, (in print).

[4] H. M. Mooney, and W. W. Wetzel. The potentials about a point electrode and apparent resistivity curves for a two-, three-, and four-layer earth, p. 146 (Univ. of Minn. Press, Minneapolis, Minn., 1956).

[5] C. Zablocki. Analog studies of induced polarization over a layered earth, Geophysics, 22, 502 (1957).

[6] J. R. Wait. Mutual coupling of loops lying on the ground, Geophysics, 19, 290 (1954).

[7] J. R. Wait. Mutual electromagnetic coupling of loops over a homogeneous ground, Geophysics, 20, 630 (1955).

[8] L. B. Slichter and L. Knopoff. Field of an alternating dipole on the surface of a layered earth, Geophysics, 24, 77 (1959).

[9] J. R. Wait. Induction by an oscillating magnetic dipole over a two-layered earth, Appl. Sci. Research, $\boldsymbol{\gamma}, 73$ (1958).

[10] C. P. Smythe, and C. S. Hitchcock. Dipole rotation in crystalline solids, J. Am. Chem. Soc., 54, 4631 (1932).

(Paper 64D5-79) 